


\title{
Habilidades sociais educativas paternas e comportamento infantil
}

\author{
Parental social educational skills and child behavior
}

\author{
Aline Costa Fantinato ${ }^{[a]}$, Fabiana $\mathrm{Cia}^{[b]}$
}

\footnotetext{
${ }^{\text {[a] }}$ Mestre e doutoranda em Educação Especial pela Universidade Federal de São Carlos, São Carlos, SP - Brasil, e-mail:

alinefantinato@hotmail.com

${ }^{[b]}$ Doutora em Educação Especial e professora da Universidade Federal de São Carlos, São Carlos, SP - Brasil, e-mail:

fabianacia@hotmail.com
}

Recebido: 04/11/2012 Received: 04/11/2012

Aprovado: 25/06/2013 Approved: 06/25/2013

\section{Resumo}

As práticas educativas utilizadas pelos pais podem contribuir tanto para a instalação e manutenção de problemas de comportamentos como de comportamentos socialmente adequados apresentados por crianças. As habilidades sociais educativas têm sido apontadas como tendo forte relação com os comportamentos apresentados pelas crianças, sendo um indicativo de boas práticas educativas. Diante disso, os objetivos do presente estudo foram: (a) comparar as habilidades sociais educativas entre pais de crianças que possuem atraso no desenvolvimento e crianças que não possuem atraso no desenvolvimento; (b) comparar os problemas de comportamento entre os grupos de crianças e (c) examinar as relações existentes entre as habilidades sociais educativas paternas e os problemas de comportamento infantil. Participaram do estudo quarenta pais, sendo quatorze pais de crianças com atraso no desenvolvimento (G1) e 26 pais de crianças sem indicação de atraso no desenvolvimento (G2). Os pais responderam ao Roteiro de Entrevista de Habilidades Sociais Educativas Parentais (RE-HSE-P) e ao Strenghts and Difficulties (SDQ) para avaliar os comportamentos infantis. Averiguou-se que pais de crianças sem atraso no desenvolvimento apresentam melhor repertório de habilidades sociais educativas do que os pais de crianças com atraso no desenvolvimento. Em relação aos comportamentos infantis, os resultados mostraram que crianças com atraso no desenvolvimento apresentam mais problemas de comportamento do que crianças sem atraso. Além disso, notou-se que as habilidades sociais educativas dos pais se correlacionam negativamente aos problemas de comportamento das crianças, se constituindo como um fator de proteção ao desenvolvimento infantil.

Palavras-chave: Habilidades sociais educativas. Pai. Pré-escolar. Problemas de comportamento.

\section{Abstract}

Educational practices used by parents can contribute to both installation and maintenance of behavior problems and socially appropriate behaviors displayed by children. The social educational skills have been identified as having strong relationship with the behaviors exhibited by the children, being an indicative of good educational practices. Therefore, the aims of this study were: (a) to compare the social educational skills among parents of children who have developmental 
delay and children who do not have developmental delay, (b) to compare the behavior problems among groups of children and (c) to examine the relationship between parental social educational skills and child behavior problems. 40 parents, 14 of them parents of children with developmental delay (G1) and 26 parents of children with no indication of developmental delay (G2) have participated in the study. Parents answered the Parental Social Educational Skills Script Interview (RE-HSE-P) and SDQ-Strengths and Difficulties to assess child behavior. It was found that parents of children without developmental delay have better social educational skills than parents of children with developmental delay. In relation to child behaviors, results showed that children with developmental delay have more behavior problems than children without delay. Furthermore, it was found that parental social educational skills correlate negatively with children's behavior problems, constituting themselves as a protective factor to the development of the child.

Keywords: Social educational skills. Parent. Preschool. Behavior problems.

\section{Introdução}

O presente estudo aborda a temática das habilidades sociais educativas paternas e sua relação com os comportamentos apresentados por crianças pré-escolares, considerando o campo teórico-prático do Treinamento de Habilidades Sociais e a Psicologia do Desenvolvimento Infantil. Ressaltase que muitas crianças em idade pré-escolar apresentam problemas de comportamento e não têm o desempenho escolar esperado para sua faixa etária, necessitando de maior apoio na realização de suas atividades. Desta forma, torna-se de extrema importância a investigação de fatores que podem interferir no desenvolvimento infantil, como as habilidades sociais educativas dos pais.

\section{Habilidades sociais educativas e problemas de comportamento}

O modo que os pais interagem com seus filhos exerce influência direta sob o comportamento destes. Pais que usam práticas educativas positivas, ou seja, que se envolvem com os filhos, se preocupam e têm uma relação afetiva tendem a ter filhos com comportamentos socialmente adequados e com bom repertório de habilidades sociais. Por outro lado, quando os pais não se envolvem com os filhos e usam práticas negativas, aumenta a probabilidade de a criança vir a apresentar problemas de comportamento (Bolsoni-Silva \& Del Prette, 2002; Bolsoni-Silva, Del Prette \& Oishi, 2003; Bolsoni-Silva \& Marturano, 2007; Leme \& Bolsoni-Silva, 2010).
Sabe-se que as crianças aprendem por observação/modelação, instrução e consequenciação (Del Prette \& Del Prette, 2005), sendo assim, é possível supor que crianças que estão expostas a práticas parentais negativas, estejam aprendendo a se comportar dessa maneira com seus pares, além de esses pais reforçarem com maior frequência os comportamentos inadequados emitidos pela criança do que seus comportamentos socialmente adequados (Bolsoni-Silva \& Marturano, 2007; Gresham, 2009).

Os problemas de comportamento infantil são definidos como déficits no repertório de habilidades sociais do indivíduo, sendo que esses comportamentos concorrem com os comportamentos adequados e acabam por inibir determinada habilidade social (Gresham, 2009). Já para Bolsoni-Silva (2003) os problemas de comportamento seriam "déficits ou excessos comportamentais, que prejudicam a interação da criança com pares e adultos de sua convivência" (p. 9), podendo ser externalizantes (expressos em relação à outra pessoa) ou internalizantes (expressos para si mesmo). Tais déficits ou excessos também prejudicam o acesso às novas contingências de reforçamento e, por consequência, aos repertórios de aprendizagem (Bolsoni-Silva \& Del Prette, 2002).

De acordo com Bolsoni-Silva e Marturano (2007), a relação entre pais e filhos se constitui como uma interação social, que pode ser tanto positiva como negativa. Neste sentido, o campo teórico-prático das habilidades sociais colabora para o entendimento dessa relação como também na identificação das habilidades sociais dos pais que podem estar colaborando para a interação com seus filhos.

Entende-se por habilidades sociais as distintas classes de comportamento do individuo que 
colaboram para a interação com o outro; no entanto, um comportamento social só vai ser considerado como habilidade social quando contribui para a competência social (Del Prette \& Del Prette, 2001; 2005). Já as habilidades sociais educativas são aquelas intencionalmente voltadas para a promoção e aprendizagem do outro e, por isso, estão relacionadas ao contexto educacional e familiar. Para as habilidades sociais serem consideradas como educativas, devem provocar mudanças no repertório do aprendiz (Del Prette \& Del Prette, 2001). Para Silva (2000), as habilidades sociais educativas são as habilidades sociais dos pais aplicáveis à prática educativa.

Del Prette e Del Prette (2008) descrevem quatro classes amplas que compõem o sistema de habilidades sociais educativas, que são: estabelecer contextos interativos potencialmente educativos; transmitir ou expor conteúdos sobre habilidades sociais; estabelecer limites e/ou disciplina e monitorar positivamente. Já Bolsoni-Silva (2008) divide as habilidades sociais educativas em classes de comunicação, expressão de sentimentos e enfrentamento e estabelecimento de limites.

Vários estudos mostram que pelo menos um dos comportamentos parentais que compõem as habilidades sociais educativas é crucial para a promoção de comportamentos socialmente adequados nas crianças e para prevenir a emissão de problemas de comportamento (Bolsoni-Silva \& Del Prette, 2002; Cia \& Barham, 2009; Ferreira \& Marturano, 2002).

A relação entre habilidades sociais educativas parentais e comportamento infantil é evidenciada nos estudos de Bolsoni-Silva e Del Prette (2002), Bolsoni-Silva et al. (2003), Bolsoni-Silva e Marturano (2007), Villas Boas e Bolsoni-Silva (2010) BolsoniSilva e Loureiro (2011) mostrando que crianças com comportamentos socialmente adequados têm pais com repertório de habilidades sociais educativas mais elaborado. No entanto, tais estudos não focam na figura paterna e não comparam crianças que apresentam indicação escolar de necessidade de apoio e atenção com as que não apresentam tal necessidade.

Sabe-se que o papel do pai passou por transformações ao longo do tempo. Em uma breve revisão histórica, pode-se notar que a figura paterna estava atrelada ao sustento financeiro da família e pouco participativo na vida dos filhos, ou seja, não se envolvia afetivamente com a prole. A entrada da mulher no mercado de trabalho foi um fator que colaborou para que o homem mudasse essa postura, se afastando então, deste papel distante da família, passando para um pai participativo, envolvido afetivamente e que não se coloca apenas no papel de provedor financeiro (Bertolini, 2002; Jablonski, 1999; Lewis \& Dessen, 1999; Cabrera, Tamis-Lemonda, Bradley, Hofferth, \& Lamb, 2000).

A fim de ilustrar a importância do pai para o desenvolvimento infantil, encontra-se o estudo de Cia e Barham (2009). As autoras realizaram um estudo para relacionar o envolvimento paterno com as habilidades sociais e problemas de comportamento dos filhos. Participaram 97 casais de crianças de $1^{\text {a }}$ e $2^{\text {a }}$ séries $^{1}$ do Ensino Fundamental e vinte professoras. Os resultados mostraram que quanto maior o índice de problemas de comportamento das crianças, menor o envolvimento do pai nas atividades escolares, culturais e de lazer e comunicação com os filhos. Em contrapartida, o repertório de habilidades sociais das crianças estava positivamente correlacionado com a frequência do envolvimento paterno. Desta forma, conclui-se que o bom envolvimento entre pais e filhos é preditor de habilidades sociais, sendo considerado um mecanismo de proteção ao desenvolvimento infantil.

Levando em consideração que a figura paterna ainda é pouco estudada no contexto brasileiro, os objetivos do presente estudo foram: (a) comparar as habilidades sociais educativas entre pais de crianças que possuem atraso no desenvolvimento e crianças que não possuem atraso no desenvolvimento; (b) comparar os problemas de comportamento entre crianças que possuem atraso no desenvolvimento e crianças que não possuem atraso no desenvolvimento e (c) examinar as relações existentes entre as habilidades sociais educativas paternas e os problemas de comportamento infantil.

\section{Método}

\section{Participantes}

Participaram da pesquisa quarenta pais (homens) de crianças pré-escolares. Tais crianças

\footnotetext{
1 Utilizou-se o termo série, pois no ano em que a pesquisa foi desenvolvida, era essa nomenclatura utilizada.
} 
tinham média de idade de 4,7 anos, sendo trinta do sexo masculino e dez do sexo feminino. A média de idade dos pais era de 37 anos. Todos os pais eram casados ou viviam como casados. Participaram também treze professores, sendo doze do sexo feminino e um do sexo masculino, com idade média igual a 42 anos, variando de 27 a 52. Os professores participantes foram aqueles cujos pais das crianças aceitaram participar da pesquisa. Ressalta-se que alguns professores avaliaram mais de uma criança de uma mesma sala.

Os participantes foram divididos em dois grupos: (G1) pais de crianças pré-escolares que apresentavam, segundo a opinião da professora, atraso no desenvolvimento ${ }^{2}$ e (G2) pais de crianças pré-escolares que não apresentavam atraso no desenvolvimento, segundo a avaliação dos professores. Para verificar a homogeneidade dos grupos, aplicou-se o teste $t$ e chi-quadrado e não constaram diferenças estatisticamente significativas entre os grupos.

Foram utilizados como critérios para ser participante: o pai e o professor se interessarem em participar da pesquisa, o pai estar empregado ou exercendo atividade remunerada, a criança estar matriculada em uma pré-escola e morar com ambos os pais (biológicos).

\section{Local de coleta de dados}

O contato com os pais e com os professores ocorreu em quatro pré-escolas municipais de uma cidade de pequeno porte do interior de São Paulo. As escolas foram selecionadas aleatoriamente e estavam distribuídas geograficamente pelo município, a fim de garantir maior diversidade dos participantes. A entrevista com os pais ocorreu no local de preferência destes (nas dependências das pré-escolas ou na casa dos participantes) e a coleta com os professores ocorreu nas pré-escolas onde lecionavam. $\mathrm{Na}$ realização de todas as entrevistas, foi assegurado um ambiente silencioso e sigiloso aos participantes.

\footnotetext{
2 Foi definido crianças que apresentam atraso no desenvolvimento aquelas apontadas pelos professores por necessitarem de mais auxílio e estimulação comparado com as demais crianças.
}

\section{Aspectos éticos}

A pesquisa foi aprovada pelo Comitê de Ética em Pesquisa da Universidade Federal de São Carlos (Parecer no 347/2011). Todos os participantes receberam o Termo de Consentimento Livre e Esclarecido, como também informações acerca dos objetivos da pesquisa e os procedimentos da coleta de dados. Além disso, foi assegurado o sigilo da identidade dos participantes e estes tiveram total autonomia em relação à participação no estudo, podendo desistir a qualquer momento.

\section{Instrumentos/Pais}

- Roteiro de Entrevista de Habilidades Sociais Educativas Parentais (RE-HSE-P) (BolsoniSilva, Marturano \& Loureiro, 2011):

Esse instrumento focaliza as seguintes HSE-P: manter conversação; fazer perguntas; expressar sentimentos positivos e negativos; expressar opinião; estabelecer limites; cumprir promessas; concordar com cônjuge quanto à educação do filho; discriminar e consequenciar comportamentos adequados dos filhos; demonstrar carinho; responder as perguntas de sexualidade do filho e autoavaliar-se quanto a "erros" na forma de educar. Cada tópico é introduzido com uma questão fechada, sendo que, em algumas, o respondente tem três opções de resposta: frequentemente, algumas vezes ou nunca/quase nunca e em outras questões as opções são sim ou não. São cinco categorias estabelecidas pelo instrumento para a classificação das respostas: habilidades sociais educativas parentais, habilidades sociais da criança, contexto, práticas educativas negativas e problemas de comportamento. Deve-se atribuir 0 para as respostas nunca/quase nunca, 1 para algumas vezes e 2 para frequentemente.

0 questionário fornece três conjuntos de informações: frequência das habilidades sociais educativas; número de itens para avaliações de conteúdo do comportamento dos pais e dos filhos e frequência para avaliações de conteúdo do comportamento dos pais e dos filhos. Por meio dessas informações, os escores de cada categoria comportamental são classificados em clínico, limítrofe e não clínico. Para análise da consistência interna da escala, com os dados coletados neste estudo, foram considerados os itens de frequência, apresentando um $\alpha=0,85$. 
Ressalta-se que no presente estudo serão apresentados apenas os dados referentes às questões de frequência.

- Questionário de Capacidades e Dificuldades (SDQ), elaborado por Goodman (1997) e validado para o contexto brasileiro por FleitlichBilyk e Goodman (2001):

É um instrumento breve, utilizado para rastreamento de problemas comportamentais e capacidades de crianças e adolescentes (4 a 16 anos). 0 questionário apresenta três versões, a de autoaplicação, indicada para adolescentes entre 11 e 16 anos; a versão para pais e/ou educadores e a versão para professores. Neste estudo foi utilizada a versão para pais e professores. 0 questionário é composto por 25 itens, contidos em cinco escalas: Sintomas Emocionais, Problemas de Conduta, Hiperatividade, Problemas de Relacionamento com Colegas e Comportamento Pró-social.

As alternativas para resposta são expostas em cada questão e apresentam como opções: falso, mais ou menos verdadeiro e verdadeiro. Para a pontuação dos itens, atribui-se 0 para "alternativas falso", 1 para "mais ou menos verdadeiro" e 2 para "verdadeiro". Após atribuir para cada item o valor correspondente, deve-se somar a pontuação de cada escala para obter o escore total de cada escala e a pontuação total das dificuldades, que se dá pela soma dos resultados das quatro primeiras escalas, sendo a pontuação máxima igual a 40. Para cada uma das escalas, a pontuação pode variar de zero a dez se todos os cinco itens forem completados. 0 resultado de cada escala pode ser avaliado se ao menos três itens forem respondidos. 0 comportamento da criança pode ser classificado em normal, limítrofe ou anormal de acordo com a pontuação em cada escala. Assim, o instrumento permite verificar a classificação total das dificuldades, como também verificar o foco dos problemas comportamentais da criança por meio de cada escala. A análise da consistência interna das escalas, com base nos dados da presente pesquisa, mostrou $\alpha=0,70$ na versão para pais.

\section{Procedimento de coleta de dados}

Inicialmente foi realizado o contato com a direção de cada pré-escola a fim de explicar os objetivos da pesquisa. Com o consentimento da direção, entrou-se em contato com os professores para saber do interesse de cada um. 0 contato com os pais foi feito por meio de reuniões escolares e para os pais que não estavam presentes, foi enviado um convite pelo caderno da criança. Posteriormente, foi agendado o local e data para a entrevista com os pais. Após a coleta de dados com os pais, a pesquisadora entrou em contato com a professora de cada criança, para indicar se a criança apresentava atraso no desenvolvimento. A indicação de atraso no desenvolvimento deu-se de acordo com a opinião do professor, e os professores apontaram como justificativas: o aluno ter dificuldades em realizar as atividades sozinho, necessitando de maior apoio e atenção do professor para a realização das atividades, demandar mais tempo em relação aos colegas para a realização das atividades e ter dificuldades na execução das atividades.

As respostas ao RE-HSE-P foram gravadas em áudio, e depois anotadas no livro de aplicação, de acordo com as instruções do manual. A aplicação do SDQ também foi feita em forma de entrevista, porém, não foi gravada e as respostas eram anotadas após a resposta do participante.

\section{Procedimento de análise de dados}

Para a análise dos dados obtidos por meio do REHSE-P deve-se primeiramente somar a frequência de cada categoria comportamental analisada. Feita a soma, deve-se consultar o manual para classificar a categoria comportamental em clínico, limítrofe e não clínico, de acordo com os escores apresentados (Bolsoni-Silva et al.,2011).

Para analisar a pontuação total das dificuldades no $S D Q$ foram somados os resultados das quatro primeiras escalas (Sintomas Emocionais, Problemas de Conduta, Hiperatividade e Problemas de Relacionamento com Colega), sendo que a pontuação pode variar de zero a quarenta (o resultado total será considerado se ao menos doze dos vinte itens relevantes foram completados). Além disso, foram gerados escores de cada uma das cinco escalas, pela soma dos itens que as compõem, podendo variar a pontuação de zero a dez para cada escala. Com base no escore total das dificuldades e das cinco escalas que compõem o SDQ, as crianças são classificadas em normal, limítrofe e anormal (FleitlichBilyk \& Goodman, 2001). 
Para comparar o repertório de habilidades sociais educativas parentais e os problemas de comportamento das crianças entre os grupos de G1 e G2, foi utilizado o teste $t$. Para avaliar as relações entre as variáveis paternas e infantis foi utilizado o teste de correlação de Pearson. Para todos os testes foi utilizado o programa SPSS - For Windows. 0 nível de significância adotado foi $p<0,1$, para as análises comparativas entre os grupos e de $p<0,05$, para as análises de correlações.

\section{Resultados}

A Tabela 1 compara as habilidades sociais educativas entre pais de crianças com atraso no desenvolvimento e pais de crianças sem atraso no desenvolvimento.

Tabela 1 - Habilidades sociais educativas paternas: comparação entre os grupos G1 e G2

\begin{tabular}{|c|c|c|c|c|c|c|}
\hline \multirow[b]{2}{*}{ Item } & \multicolumn{2}{|c|}{$\begin{array}{c}\text { G1 } \\
(\mathrm{N}=14) \\
\end{array}$} & \multicolumn{2}{|c|}{$\begin{array}{c}\text { G2 } \\
(N=26) \\
\end{array}$} & \multicolumn{2}{|c|}{ Teste- $t$} \\
\hline & Média & D. $P$. & Média & D. $P$. & $t$ & $D f$ \\
\hline $\begin{array}{l}\text { Você conversa } \\
\text { com seu filho? }\end{array}$ & 1,86 & 0,36 & 1,88 & 0,33 & ns & ns \\
\hline $\begin{array}{l}\text { Você expressa } \\
\text { seus sentimen- } \\
\text { tos negativos a } \\
\text { seu filho? }\end{array}$ & 1,36 & 0,63 & 1,73 & 0,53 & $1,98^{*}$ & 38 \\
\hline $\begin{array}{l}\text { Você encontra } \\
\text { dificuldades } \\
\text { para cumprir } \\
\text { as promessas } \\
\text { feitas a seu } \\
\text { filho? }\end{array}$ & 0,50 & 0,76 & 0,15 & 0,37 & $1,95+$ & 38 \\
\hline $\begin{array}{l}\text { Você e seu } \\
\text { cônjuge se } \\
\text { entendem } \\
\text { quanto à forma } \\
\text { de educar seu } \\
\text { filho? }\end{array}$ & 1,14 & 0,77 & 1,65 & 0,56 & $2,41^{*}$ & 38 \\
\hline $\begin{array}{l}\text { Seu filho faz } \\
\text { coisas de que } \\
\text { você não gosta? }\end{array}$ & 1,07 & 0,27 & 0,88 & 0,43 & ns & ns \\
\hline
\end{tabular}

Nota. A frequência variou de 0 a 2 .

$+\mathrm{p}<0,1 ;^{*} \mathrm{p}<0,05$; ns: não apresenta diferença estatisticamente significativa.

Como mostram os dados da Tabela 1, pais do G2 apresentaram médias maiores com diferenças significativas nos itens referentes à expressão de sentimentos negativos $(t(38)=1,98, p<0,05)$ e no entendimento do casal em relação à educação do filho $(\mathrm{t}(38)=2,41, \mathrm{p}<0,05)$. Enquanto isso, pais do G1 parecem ter mais dificuldade para cumprir as promessas feitas aos filhos, uma vez que esse item apresentou tendência à diferença estatisticamente significativa ( $t(38=1,95, \mathrm{p}<0,1)$.

A Tabela 2 mostra a avaliação dos pais sobre os comportamentos dos filhos, comparando os grupos de crianças com atraso no desenvolvimento e sem atraso no desenvolvimento.

Tabela 2 - Avaliação das escalas do SDQ pelos pais: Comparação entre os grupos G1 e G2

\begin{tabular}{|c|c|c|c|c|c|c|}
\hline \multirow[t]{2}{*}{ Escalas } & \multicolumn{2}{|c|}{$\begin{array}{c}\text { G1 } \\
(\mathrm{N}=14)\end{array}$} & \multicolumn{2}{|c|}{$\begin{array}{c}G 2 \\
(N=26)\end{array}$} & \multicolumn{2}{|c|}{ Teste- $t$} \\
\hline & Média & D. $P$. & Média & D. $P$. & $t$ & $D f$ \\
\hline $\begin{array}{l}\text { Sintomas } \\
\text { emocionais }\end{array}$ & 3,00 & 1,41 & 3,23 & 1,63 & ns & ns \\
\hline $\begin{array}{l}\text { Problemas de } \\
\text { conduta }\end{array}$ & 2,21 & 1,25 & 2,12 & 1,68 & ns & ns \\
\hline Hiperatividade & 4,86 & 1,56 & 4,96 & 3,09 & ns & ns \\
\hline $\begin{array}{l}\text { Problemas de } \\
\text { relacionamento } \\
\text { com colegas } \\
\end{array}$ & 2,50 & 2,21 & 1,00 & 1,30 & $2,72 *$ & 38 \\
\hline $\begin{array}{l}\text { Comportamen- } \\
\text { tos pró-sociais }\end{array}$ & 8,57 & 1,28 & 8,96 & 1,25 & ns & $\mathrm{ns}$ \\
\hline $\begin{array}{l}\text { Pontuação total } \\
\text { das dificuldades }\end{array}$ & 12,57 & 3,80 & 11,27 & 5,64 & ns & ns \\
\hline
\end{tabular}

Nota. ${ }^{*} \mathrm{p}<0,05$; ns: não apresenta diferença estatisticamente significativa.

De acordo com a avaliação dos pais, apenas a escala de problemas de relacionamento com colegas apresentou diferença estatisticamente significativa $(\mathrm{t}(38)=2,72, p<0,05)$, sendo que as crianças do G1 apresentaram média maior neste item, ou seja, essas crianças podem ter mais dificuldades de interação com seus pares.

A Tabela 3 ilustra as correlações encontradas entre as escalas de habilidades sociais educativas dos pais e os comportamentos infantis.

A Tabela 3 mostra que o fato de os pais conversarem com seus filhos esteve negativamente correlacionado aos problemas de conduta $(\mathrm{r}=-0,571$, $p<0,001)$, hiperatividade $(\mathrm{r}=-0,418, p<0,01)$ e pontuação total das dificuldades ( $\mathrm{r}=-0,399, p<0,05)$, ou seja, quanto mais os pais conversavam com seus filhos, menor o índice destes problemas de comportamento apresentados pelas crianças. 
Tabela 3 - Correlações significativas entre habilidades sociais educativas paternas e problemas de comportamento dos filhos na opinião de pais

\begin{tabular}{|c|c|c|c|c|c|c|}
\hline \multirow[b]{2}{*}{ Itens } & \multicolumn{5}{|c|}{ Teste de Pearson $r$} & \multirow[b]{2}{*}{$\begin{array}{l}\text { Pontuação total } \\
\text { das dificuldades }\end{array}$} \\
\hline & $\begin{array}{c}\text { Sintomas } \\
\text { emocionais }\end{array}$ & $\begin{array}{l}\text { Problemas } \\
\text { de conduta }\end{array}$ & Hiperatividade & $\begin{array}{l}\text { Problemas de } \\
\text { relacionamen- } \\
\text { to com colegas }\end{array}$ & $\begin{array}{l}\text { Comporta- } \\
\text { mentos } \\
\text { pró-sociais }\end{array}$ & \\
\hline $\begin{array}{l}\text { Você conversa com } \\
\text { seu filho }\end{array}$ & --- & $-0,571^{* * *}$ & $-0,418^{* *}$ & --- & --- & $-0,399 *$ \\
\hline $\begin{array}{l}\text { Você expressa seus } \\
\text { sentimentos negativos } \\
\text { ao seu filho }\end{array}$ & $-0,346^{*}$ & --- & --- & --- & --- & --- \\
\hline $\begin{array}{l}\text { Você tem dificuldade } \\
\text { em cumprir promes- } \\
\text { sas ao seu filho }\end{array}$ & --- & $0,372^{*}$ & $0,313^{*}$ & --- & --- & $0,403^{* *}$ \\
\hline $\begin{array}{l}\text { Você e sua esposa se } \\
\text { entendem quanto à } \\
\text { forma de educar o } \\
\text { filho }\end{array}$ & --- & --- & --- & --- & $0,416^{* *}$ & $-0,379 *$ \\
\hline $\begin{array}{l}\text { Seu filho faz coisas } \\
\text { que você não gosta }\end{array}$ & --- & --- & $0,321 *$ & --- & --- & $0,371^{*}$ \\
\hline
\end{tabular}

Nota. ${ }^{*} p<0,05 ;{ }^{* *} p<0,01 ;{ }^{* * *} p<0,001$.

A expressão de sentimentos negativos do pai para com seu filho esteve negativamente correlacionada com os sintomas emocionais infantis ( $\mathrm{r}=-$ $0,346, p<0,05)$ e a expressão de opiniões do pai para seu filho esteve negativamente correlacionada com problemas de conduta $(\mathrm{r}=-0,419, p<0,01)$, hiperatividade $(\mathrm{r}=-0,375, p<0,05)$ e pontuação total das dificuldades $(\mathrm{r}=-0,473, p<0,01)$ e positivamente correlacionada com os comportamentos pró-sociais dos filhos $(\mathrm{r}=0,478, p<0,01)$.

A dificuldade dos pais em cumprirem as promessas feitas aos filhos apresentou correlação positiva com os problemas de conduta $(\mathrm{r}=0,372$, $p<0,05)$, hiperatividade $(\mathrm{r}=0,313, p<0,05)$ e pontuação total das dificuldades dos filhos $(r=0,403$, $p<0,01)$. Por outro lado, os resultados apontaram correlação positiva entre o entendimento do casal em relação à educação dos filhos com os comportamentos pró-sociais infantis $(\mathrm{r}=0,416, p<0,01)$ e correlação negativa com a pontuação total das dificuldades dos filhos $(r=-0,379, p<0,05)$. Desta forma, pode-se supor que quanto melhor o relacionamento conjugal, maior o índice de comportamentos adequados dos filhos. Os comportamentos infantis que desagradavam os pais apresentaram correlações positivas com a escala de hiperatividade e pontuação total das dificuldades dos filhos.

\section{Discussão}

De modo geral, percebeu-se que os pais do G2 apresentam mais habilidades sociais educativas do que pais do G1. Esses resultados confirmam em parte dados da literatura que apontam que pais de crianças com comportamentos socialmente adequados possuem melhor repertório de habilidades sociais educativas (Bolsoni-Silva \& Del Prette, 2002; Bolsoni-Silva \& Marturano, 2007).

Em relação aos comportamentos infantis, notou-se diferença estatisticamente significativa apenas na escala de problemas de relacionamento com colegas, sendo que as crianças do G1 apresentaram média maior, ou seja, apresentam mais dificuldades nas relações com os colegas.

A amizade na infância é apontada na literatura como um importante fator para o desenvolvimento social e emocional das crianças, pois é por meio das amizades que a criança cria um contexto de cooperação e tem modelo para a aprendizagem e exercício de relacionamento e de resoluções de problemas com os pares (Castro, Melo \& Silvares, 2003; Del Prette \& Del Prette, 2005; Dessen, Torres \& Szelbracikowski, 2008). Para Del Prette e Del Prette (2005), a dificuldade em fazer amizades pode estar relacionada ao déficit em habilidades sociais. As crianças do G1 podem ter mais dificuldades em 
tomar iniciativas em interações sociais ou mesmo na comunicação, o que pode favorecer a não ocorrência de habilidades sociais importantes para o convívio das crianças com seus pares. Soma-se o fato que fazer amizade favorece no desenvolvimento de outras habilidades sociais, tais como: fazer perguntas pessoais, responder perguntas, falar de si, sugerir atividades, apresentar-se e cumprimentar, elogiar e aceitar elogios, cooperar e oferecer ajuda, iniciar e manter conversação e comunicar-se de forma apropriada. Keiley, Bates, Dodge e Petit (2000) complementam que a habilidade de fazer amizade também tem sido apontada como importante para diminuir os problemas de comportamento internalizantes das crianças.

Pode-se inferir a possibilidade de que a dificuldade em interagir com pares apresentada pelas crianças do G1 está relacionada à maior necessidade de apoio e atenção exposta por este grupo. Supõe-se que essas crianças não tenham modelos positivos de interação, o que pode dificultar ainda mais a relação com os colegas.

No que refere-se às correlações encontradas entre as variáveis, percebeu-se que, quanto mais os pais conversavam com seus filhos, menor o índice de problemas de conduta, hiperatividade e pontuação total das dificuldades das crianças.

A comunicação verbal entre pais e filhos colabora para a maximização das interações positivas e possibilita aproximação entre os mesmos. Como visto nos dados do presente estudo (Tabela 1), pais de ambos os grupos conversavam e faziam perguntas aos seus filhos, mostrando interesse e preocupação com a vida da criança, o que pode ser entendido como fator de proteção ao desenvolvimento infantil, já que os resultados desta pesquisa apontaram para correlações negativas com os problemas de comportamento das crianças. É importante que os pais emitam esse tipo de comportamento, como questionar como foi o dia da criança, suas conquistas e dificuldades, pois favorece o fortalecimento do vínculo entre eles, além das crianças se sentirem amadas e importantes para os pais (Gomide, 2004).

A expressão de sentimentos negativos ao filho apresentou correlação negativa com a escala de sintomas emocionais, ou seja, quanto mais os pais expressavam seus sentimentos negativos aos filhos, menor o índice de sintomas emocionais das crianças. De acordo com Bolsoni-Silva e Marturano (2002), quando os pais expressam seus sentimentos em relação aos comportamentos dos filhos, colaboram para que a criança discrimine seus comportamentos adequados e inadequados.

Quanto à expressão de opiniões ao filho, notou-se correlação negativa com o índice de problemas de conduta, hiperatividade e pontuação total das dificuldades e correlação positiva com comportamentos pró-sociais, ou seja, o pai expressar sua opinião aos filhos pode ser um indicativo de fator de proteção para o desenvolvimento infantil.

A dificuldade dos pais em cumprir promessas teve correlação com os índices de problemas de conduta, hiperatividade e pontuação total das dificuldades apresentadas pelas crianças. Quando os pais fazem alguma promessa ao filho e não cumprem, as crianças podem se sentir enganadas e acabam por prejudicar o relacionamento entre pais e filhos. Por outro lado, quando cumprem com o prometido servem de modelo e transmitem mais confiança ao filho (Bolsoni-Silva \& Marturano, 2002). Sendo assim, entende-se que o fato de os pais não cumprirem as promessas que fazem aos filhos pode ser um indicativo de fator de risco a problemas comportamentais infantis.

O entendimento do casal em relação à educação do filho teve correlação positiva com os comportamentos pró-sociais e negativa com a pontuação total das dificuldades das crianças. Quando o casal concorda, deixa claro para a criança os comportamentos que deve ou não emitir, assim como os pais tendem a usar menos práticas negativas na interação com os filhos.

Os comportamentos dos filhos que não agradavam aos pais apresentaram correlação positiva com a escala de hiperatividade e pontuação total das dificuldades. Provavelmente as crianças emitem problemas de comportamento no ambiente familiar que chamam a atenção dos pais e que não os agradavam. Tais problemas podem ser emitidos em outros contextos, o que requer a habilidade dos pais de além de identificar, conseguir interromper a ocorrência dos problemas, o que exige dos pais práticas educativas positivas e um repertório de habilidades sociais educativas elaborado (Bolsoni-Silva \& Loureiro, 2011; Bolsoni-Silva, Silveira \& Marturano, 2008; Cia, Barham \& Fontaine, 2010).

Desta forma, percebeu-se que as habilidades sociais educativas dos pais podem se constituir como fatores de proteção ao desenvolvimento infantil, já que, quando os pais apresentam variedade, como 
frequência destes comportamentos, os filhos não emitem ou emitem com baixa frequência comportamentos problemáticos e emitem comportamentos sociais.

Diante do exposto, é possível concluir que as habilidades sociais educativas são um indicativo de fator de proteção ao desenvolvimento infantil, já que pais que apresentam melhor repertório de habilidades sociais educativas dão modelos mais adequados e têm melhor interação com os filhos. Deste modo, salienta-se a importância de intervenções com pais para instalar e/ou aperfeiçoar seu repertório de habilidades sociais educativas e de práticas educativas, assim como um trabalho com crianças, incluindo crianças com e sem necessidades educacionais para melhorar o repertório de habilidades sociais dessas crianças, diminuindo os comportamentos inadequados.

\section{Considerações finais}

0 presente estudo focou a figura paterna, o que ainda é pouco explorado no contexto brasileiro, buscando a relação existente entre os comportamentos paternos na interação com os filhos e os comportamentos infantis. Notou-se que pais de crianças sem indicação escolar de atraso no desenvolvimento emitem com maior frequência habilidades sociais educativas na interação com seus filhos, como concordar com o cônjuge em relação à educação da criança, por exemplo. Já em relação aos comportamentos infantis, os grupos apresentaram poucas diferenças, mas as crianças do G1 apresentaram maior escore na escala de relacionamento com colegas.

Por meio dos resultados foi possível observar a existência de relação entre as habilidades sociais educativas paternas e os comportamentos infantis.

Como limitações do estudo pode-se apontar o número de participantes dos grupos e as variáveis paternas e infantis terem sido obtidas por meio de relato verbal. Pesquisas futuras com maior número de participantes e com metodologia observacional podem colaborar para suprir tais limitações.

No entanto, mesmo apresentando limitações, a presente pesquisa contribuiu para o melhor entendimento da relação entre pais e filhos e da importância desta para o desenvolvimento infantil, identificando possíveis variáveis presentes no contexto familiar que podem se constituir como fator de risco ou de proteção ao desenvolvimento infantil.

\section{Referências}

Bertolini, L. B. A. (2002). Funções paternas, maternas e conjugais na Sociedade Ocidental. In A.L.B. Bertolini (Org.). Relações entre o trabalho da mulher e a dinâmica familiar (pp. 27-31). São Paulo: Vetor.

Bolsoni-Silva, A. T. (2003). Habilidades sociais educativas, variáveis contextuais e problemas de comportamento: Comparando pais e mães de pré-escolares. Tese de Doutorado em Psicologia, Universidade de São Paulo, Ribeirão Preto, SP.

Bolsoni-Silva, A. T., Del Prette, A., \& Oishi, J. (2003). Habilidades sociais de pais e problemas de comportamento de filhos. Psicologia: Argumento, 5(9), 11-30.

Bolsoni-Silva, A. T., \& Del Prette, A. (2002). O que os pais falam sobre suas habilidades sociais e de seus filhos? Psicologia: Argumento, 3(7), 71-86.

Bolsoni-Silva, A. T., \& Loureiro, S.R. (2011). Práticas educativas parentais e repertório comportamental infantil: comparando crianças diferenciadas pelo comportamento. Paidéia, 21(48), 61-71.

Bolsoni-Silva, A. T., \& Marturano, E. M. (2002). Práticas educativas e problemas de comportamento: uma análise à luz das habilidades sociais. Estudos de Psicologia, 7(2), 227-235.

Bolsoni-Silva, A. T., \& Marturano, E. M. (2007). A Qualidade da interação positiva e da consistência parental na sua relação com problemas de comportamentos de pré-escolares. Revista Interamericana de Psicologia, 41(3), 349-358.

Bolsoni-Silva, A. T., Marturano, E.M., \& Loureiro, S.R. (2011). Roteiro de Entrevista de Habilidades Sociais Parentais - RE-HSE-P. São Paulo: Vetor.

Bolsoni-Silva, A. T. (2008). Roteiro de Entrevista de Habilidades Sociais Parentais (RE-HSE-P): Categorias e testagem preliminares. In: L.N.D. Weber (Org.). Família e desenvolvimento: Visões Interdisciplinares (pp. 145-158). Curitiba: Juruá Editora. 
Bolsoni-Silva, A. T., Silveira, F. F.,\& Marturano, E. M. (2008). Promovendo habilidades sociais educativas parentais na prevenção de problemas de comportamento. Revista Brasileira de Terapia Comportamental e Cognitiva, 10(2), 125-142.

Cabrera, N. J., Tamis-Lemonda, C. S., Bradley, R. H.; Hofferth, S., \& Lamb, M.E. (2000). Fatherhood in the Twenty-First Century. Child Development, 71(1), 127-136.

Castro, R. E. F., Melo, M. H .S., \& Silvares, E. F. M. (2003). 0 julgamento de pares de crianças com dificuldades interativas após um modelo ampliado de intervenção. Psicologia: Reflexão e Crítica, 16(2), 309-318.

Cia, F., \& Barham, E. J. (2009). O envolvimento paterno e o desenvolvimento social de crianças iniciando as atividades escolares. Psicologia em Estudo, 14(1), 67-74.

Cia, F.; Barham, E. J., \& Fontaine, A. M. G. V. (2010). Impactos de uma intervenção com pais: o desempenho acadêmico e comportamento das crianças na escola. Psicologia: Reflexão e Crítica, 23(3), 533-543.

Del Prette, Z. A. P., \& Del Prette, A. (2005). Psicologia das habilidades sociais na infância: Teoria e Prática. Petrópolis: Vozes.

Del Prette, Z. A. P., \& Del Prette, A. (2001). Psicologia das relações interpessoais: Vivências para o trabalho em grupo. Petrópolis: Vozes.

Del Prette, Z. A. P., \& Del Prette, A. (2008). Um sistema de categorias de habilidades sociais educativas. Paidéia, 18(41), 517-530.

Dessen, M. A., Torres, Y. R., \& Szelbracikowski, A. C. (2008). Comportamento interiorizado: diversidade conceitual e implicações para o desenvolvimento humano. In L. N. D. Weber (Org.). Família e desenvolvimento: Visões Interdisciplinares (pp. 159-170). Curitiba: Juruá.
Ferreira, M. C. T., \& Marturano, E. M. (2002). Ambiente familiar e os problemas de comportamento apresentados por crianças com baixo desempenho escolar. Psicologia: Reflexão e Crítica, 15(1), 35-44.

Fleitlich-Bilyk, B., \& Goodman, R. (2001). Social factors associated with child mental health problems in Brazil: Cross sectional survey. British Medical Journal, 323, 599-600.

Gomide, P.I.C. (2004). Pais presentes pais ausentes: Regras e limites. Petrópolis: Editora Vozes.

Goodman, R. (1997). The Strengths and Difficulties Questionnaire: A research note. Journal of Child Psychology and Psychiatry, 38(5), 581-586.

Gresham, F.M. (2009). Análise do comportamento aplicada às habilidades sociais. In: Z.A.P. Del Prette, \& A. Del Prette (Orgs.). Psicologia das habilidades sociais: Diversidade teórica e suas implicações (pp. 17-66). Petrópolis: Vozes.

Jablonski, B. Identidade masculina e o exercício da paternidade: de onde viemos e para onde vamos. In: T. Féres-Carneiro (Org.). Casal e Família: Entre a tradição e a transformação (pp. 55-69). Rio de Janeiro: Nau, 1999.

Keiley, M.K.; Bates, J.E.; Dodge, K.A., \& Petit, G.S. (2000). A cross-domain growth analysis:externalizing and internalizing behaviors during 8 years of childhood. Journal of Abnormal Child Psychology, 28, 161-179.

Lewis, C., \& Dessen, M.A. (1999). O pai no contexto familiar. Psicologia: Teoria e Pesquisa, 15(1), 9-16.

Silva, A.T.B. (2000). Problemas de comportamento e comportamentos socialmente adequados: Sua relação com as habilidades sociais educativas de pais. Dissertação de Mestrado em Educação Especial, Universidade Federal de São Carlos, São Carlos, SP.

Villas Boas, A.C. V. B., \& Bolsoni-Silva, A. T. (2010). Habilidades sociais educativas de mães separadas e sua relação com o comportamento de pré-escolares. Psico-USF, 15(3), 301-310. 